\title{
Comparison of Pachimetric Alterations in diabetic and non-diabetic eyes after uneventful Torsional Mode Phacoemulsification Surgery
}

\author{
Ayse Gul Kocak Altintas*, Mehmet Citirik and Cagri Ilhan \\ Department of Ophthalmology, Ulucanlar Eye Education and Research Hospital, Turkey
}

\section{Article Info \\ *Corresponding author: Ayse Gul Kocak Altintas \\ (Medical Doctor- Associated Professor) Ulucanlar Cad. No: 5906230 \\ Altindag/Ankara/Turkey \\ Tel: 90-312-3126261 \\ Fax: 90-312-3124827 \\ E-mail: aysegulkaltintas@hotmail.com}

Received: June 6, 2016

Accepted: March 22, 2017

Published: March 27, 2017

Citation: Altintas AGK, Citirik M, Ilhan C. Comparison of Pachimetric Alterations in diabetic and non-diabetic eyes after uneventful Torsional Mode Phacoemulsification Surgery. Madridge J Ophthalmol. 2017; 2(1): 12-16. doi: 10.18689/mjop-1000105

Copyright: @ 2017 The Author(s). This work is licensed under a Creative Commons Attribution 4.0 International License, which permits unrestricted use, distribution, and reproduction in any medium, provided the original work is properly cited.

Published by Madridge Publishers

\begin{abstract}
In this study we aim to evaluate in central corneal thickness (CCT) changes after uneventful phacoemulsification surgery in eyes with dense cataract in subject with diabetes mellitus (DM) and compare it with normal subjects. This study included 120 eyes of 120 patients who had cataract with nucleus density Grade 4. Out of 120 patient 49 eyes were diabetes mellitus group and 71 eyes were in control group. We found that a significant increment in preoperative CCT $(525 \mu \mathrm{m})$ comparing to postoperative CCT $(538 \mu \mathrm{m})$ in subject with DM, but in aged match normal subjects the preoperative (530 $\mu \mathrm{m})$ and postoperative $(531 \mu \mathrm{m}) \mathrm{CCT}$ was very similar at first month.
\end{abstract}

Keywords: Central Corneal Thickness; Diabetes; Phacoemulsification.

\section{Introduction}

Postoperative visual acuity mainly compromised by corneal edema after phacoemulsification surgery, because intraocular surgeries induce some degree of corneal endothelial cells changes. The transparency of cornea is dependent on barrier function of this single layer endothelial cell. The corneal endothelium is a not only acts as a physiological barrier between corneal stroma and anterior chamber but also serves as a continuous pump preserving the cornea in a dehydrated and transparency state [1-3]. Even both the quantity and quantify of endothelial cell are important to maintain corneal transparency, according to several reports cornea could be clear even supported by a few number of endothelial cells, on the other hand severe corneal edema might be occur despite the presence of an adequate number of endothelial cells. Therefore quality of the endothelial cells is certainly the most important factor for preventing corneal edema [1-5].

Several surgical factors cause endothelial cell damage during phacoemulsification surgery such as phacoemulsification technique, amount of ultrasound energy, hardness of nucleus, intra-cameral surgical manipulations including capsule tension ring or iris retractor hooks insertions [6-8].

Diabetes mellitus (DM) is one of the most common co-morbidities among people with cataract. Because increased blood glucose levels can affect ocular cells in many ways which may cause breakdown of blood aqueous barrier and endothelial dysfunction leading to corneal edema after cataract surgery $[1,4,9]$.

The aim of this study was to compare development of corneal edema by evaluating corneal thickness (CT) changes after cataract surgery in patient with DM and normal subjects. 


\section{Patients and Methods}

This study included 120 eyes of 120 patients who had cataract with nucleus density Grade 4. The current study was designed in accordance with the Declaration of Helsinki. All patients signed an informed consent about the nature of the procedure. All patients were Turkish Caucasians. Preoperative examination included visual acuity, tonometry, keratometry, detailed slit lamp examination, a-scan biometry and pachymetry. Nuclear hardness was classified clinically according to color of the nucleus and degree of fundus view from Grade 1 to Grade 5. In this study only Grade 4 with yellow amber color nucleus and poor fundus reflex were included.

The patients were excluded if they had history of any other ocular surgery, ocular trauma, prior treatment with antiVEGF agents in to the anterior chamber, receiving topical anti-glaucoma medication. Eyes had black, brunescent cataract, coexisting glaucoma, uveitis, corneal endothelial disease seen under slit-lamp examination and patient with any other systemic diseases that may have effect on corneal thickness rather than DM were not included in this study. According to Early Treatment Diabetic Retinopathy Study criteria's patient with only had Non Proliferative Diabetic Retinopathy (NPDR) and stable DM under metabolic control were included in present evaluation.

All subjects underwent surgery with local anesthesia, after a clear corneal incision, capsulorhexis was created, then multiquadrant hydrodissection and rotation were done. Phacoemulsification was performed using with torsional rotation which called ellips FX mode system by Signature phacoemulsification machine (Abbott Medical Optics, Santa Ana, CA, USA). After removing whole nuclear material by divide and conquer technique, bimanual irrigation and aspiration (I/A) was performed to remove the cortex completely. With the help of the protective effect of ophthalmic viscoelastic devices (OVD) on corneal endothelium, IOL was implanted in the capsular bag and the residual OVD was thoroughly removed by bimanual I/A. To prevent postoperative IOP spike, the rear section of the IOL surface was aspirated and the OVD trapped under the IOL was removed.

To eradicate the surgical factors which has effect on CT changes such as surgeon's experience, surgical technique and the materials, each patient was operated by the same experienced surgeon (AKA) by the same phacoemulsification devices with standardized divide and conquer technique with the same mode. In addition, the composition of the surgical set-up parameters, irrigation fluids (BSS) and OVDs were the same and the same acrylic IOL inserted with the same injector system into the capsular bag in each eye.

Pachymetric evaluation performed by noncontact LS900-Lenstar device with the patient seated upright. Each patient was evaluated day 1, day 7 and day 30 after surgery. Postoperative outcome measures were the change in central corneal thickness (CCT) between preoperative and one month later after surgery.
All parameters were evaluated using statistical package for Social Science Version 22.0 (SPSS INC, Chicago IL). Kolmogorov-Smirnov test was used for evaluation of normality data in each group. Descriptive statistics were expressed as median, minimum-maximum, for non-normally distributed variables. The dependent variables were evaluated using Wilcoxon test and independent variables were evaluated using Mann-Whitney U test.

\section{Results}

The clinical research was performed on 120 eyes of 120 patients. of these patients, 69 men (57.5\%) and 51 women $(42.5 \%)$ were available for the evaluation. The mean age was, 66.6 years (range of 41-84 years). Out of 120 patient 49 eyes were DM group (DMG) and 71 eyes were in control group (CG). Baseline preoperative demographic data are seen in Table 1. There were no statistically differences among the two groups in age and nuclear hardness of cataract. The male subjects were higher in control group than in diabetic group while the female subjects were similar in two groups. No one had any intraoperative complication such as posterior capsule rupture, vitreous loss and descemet's membrane detachment. No one had elevated IOP postoperatively, no one need any medication different from standard postoperative medication.

Table 1: Baseline preoperative demographic data

\begin{tabular}{|c|c|c|c|}
\hline \multirow[t]{2}{*}{ Group } & \multicolumn{2}{|c|}{ Sex } & Age \\
\hline & Males (n) & Females ( $n$ ) & Mean years \\
\hline DM group & 23 & 26 & $68.0 \pm 11.1$ \\
\hline Control group & 46 & 25 & $65.8 \pm 10.7$ \\
\hline
\end{tabular}

In whole group the mean preoperative CCT was $528.49 \pm$ $37.72 \mu \mathrm{m}$ (range of $436-630 \mu \mathrm{m}$ ) and the median was 535.00 $\mu \mathrm{m}$ while the mean postoperative CCT was $534.07 \pm 40.30 \mu \mathrm{m}$ (range of $440-648 \mu \mathrm{m}$ ) and the median was $538.50 \mu \mathrm{m}$. Comparison of preoperative CCT and postoperative CCT are seen in Table 2. According to Kolmogorov-Smirnov test the CCT values were not normally distributed in these 120 eyes, therefore non-parametric Wilcoxon test was applied to evaluate the difference between the preoperative and the postoperative CCT values and it was found that the postoperative $\mathrm{CCT}$ was significantly higher than that in preoperative CCT $(p=0.001)$.

Table 2: Comparison of preoperative CCT and postoperative CCT

\begin{tabular}{lccc}
\hline Group & Preoperative CCT & Postoperative CCT & p value \\
\hline DM group & $525.71 \pm 41.68 \mu \mathrm{m}$ & $538.12 \pm 47.17 \mu \mathrm{m}$ & 0.001 \\
Control group & $530.41 \pm 34.91 \mu \mathrm{m}$ & $531.27 \pm 34.87 \mu \mathrm{m}$ & 0.591 \\
Total & $528.49 \pm 37.72 \mu \mathrm{m}$ & $534.07 \pm 40.30 \mu \mathrm{m}$ & 0.001 \\
\hline
\end{tabular}

In subgroup analyses of each DMG and CG, data were not normally distributed similar to whole group and the difference between the CCT in both preoperative and the postoperative period were evaluated by Wilcoxon test too. The mean of CCT in preoperative period was $525.71 \pm 41.68 \mu \mathrm{m}$ (range 446-630 $\mu \mathrm{m})$ while it was $538.12 \pm 47.17 \mu \mathrm{m}$ (range 446-648 $\mu \mathrm{m}$ ) in postoperative period in DMG. The CCT of DMG in postoperative period was statistically significantly higher than that in preoperative period ( $\mathrm{p}: 0.001)$. 
The mean of CCT in preoperative period was $530.41 \pm 34.91$ $\mu \mathrm{m}$ (range $436-597 \mu \mathrm{m}$ ) and it was $531.27 \pm 34.87 \mu \mathrm{m}$ (range 440-599 $\mu \mathrm{m}$ ) in postoperative period in CG. The CCT of CG in both preoperative period and the 1 month after the operation was not statistically significantly different ( $p: 0.591$ ).

The mean preoperative CCT of DMG was even less than that in CG the postoperative CCT of DMG was became higher than CG's postoperative CCT. This result showed that diabetic corneas increased more than the CCT in normal subjects.

To evaluate coefficient value of CCT changes in each group (postoperative CCT/preoperative CCT) was calculated. The mean coefficient value of CCT in DMG was (1.02) also significantly higher than that in CG (1.0).

\section{Discussion}

The aim of different phacoemulsification procedures is to restore visual acuity in order to secure and fast return to normal life. It has been reported that during the phacoemulsification surgery is given free hydroxyl radicals which have destructive effect on corneal endothelium. Hyperglycemia has also toxic effects on cornea similar to other cells in the body like retina. The diabetic cornea expose 4-fold higher glucose in tear film than in normal healthy subject tears which cause it suffers from corneal cellular dysfunction, dysfunctional repair mechanisms and delayed wound healing $[1,4,5,9]$.

Even new phacoemulsification techniques and surgical materials are developed to prevent the corneal damage during the surgery; eyes with DM have still potential risk for corneal complication. Decrease in endothelial cell count after intraocular surgery is compensated by cellular enlargement, cell gliding, coalescence and re-arrangement. As far as the numbers of cells do not decrease to below of certain density estimated to 600-800 cells $/ \mathrm{mm} 2$, decompensation does not appear by enhanced endothelial function. The correlation between CCT and endothelial cell density is not clear above this limits but it correlates with endothelial functional status. Therefore $C T$ is an indirect evidence of endothelial cell functional that evaluates by pachymetry $[5,9,10]$.

In this study we aim to evaluate in CCT changes after uneventful phacoemulsification surgery in eyes with dense cataract in subject with DM and compare it with normal subjects. To compare presence of DM on corneal response to phacoemulsification surgery we preferred to hold as many factors as possible constant such as phacoemulsification mode, surgical method and the materials.

During phacoemulsification, the corneal endothelium is subjected to different types of trauma some of which are ultrasound energy, ricocheting of nuclear fragments, turbulence of the irrigating solution and mechanical trauma by contact with the IOL and instruments. The nature of cataract determines the amount of ultrasonic energy requires for nucleus emulsification and according to several reports greater phacoemulsification energy was required as nucleus hardness increased $[2,3,11,12]$. In presenting study we prefer to analyze pachymetric changes in eyes only with hard nucleus therefore we evaluate cataract with Grade 4 hardness in both DM group and the control subjects.
Different phacoemulsification techniques requires different phacoemulsification energy level, Storr-Paulsen et al [9] and Davison [10] reported that the divide-and-conquer technique spreading out more phacoemulsification power than phacoemulsification-chop technique. On the other hand it is also demonstrated that phacoemulsification-chop technique delivers more mechanical energy to break nucleus and requires a longer period for nuclear fragments mainly in the first phase of the procedure than divide-and-conquer technique [10]. Rekas et al [11] and some of other observer reported that torsional phacoemulsification mode was more effective than longitudinal mode in terms of amount of ultrasound energy deliver. To increase the efficacy of emulsification potential and decrease to mechanical negative effect on ocular structures we prefer torsional mode combined with divide-and-conquer technique. By this way when torsional movement lowers the phacoemulsification energy delivered and divide-and-conquer technique keeps as minimum manipulation.

Corneal thickness provides a measure the total amount of surgically induced endothelial injury. Reducing the other variable component as less as possible it increased the evaluating effect of comparing factor is more reliable [12]. Therefore each eye were operated by the same experienced surgeon, using with the same BSS and ophthalmic viscoelastic device and we limited our comparative evaluation to effect of DM on CT changes.

It had been reported that CCT in DM was effected by several factors such as diabetic stage and it was observed that that CCT was $570.52 \mu \mathrm{m}$ in patient with DM which was significantly higher than that in control group $(541.42 \mu \mathrm{m})$ and CCT was associated with the retinopathy stage in which CCT was $585.97 \mu \mathrm{m}$ in PDR group while it was $570.84 \mu \mathrm{m}$ in NPDR group and the lowest CCT was observed in NonDiabetic Retinopathy group $(559.80 \mu \mathrm{m})$ measured by ultrasound (US) pachymetry [13-15]. But, Ozdamar et al [16] published that even the CCT was significantly greater in eyes with DM $(564 \pm 30 \mu \mathrm{m})$ than that in control subject's CCT $(538 \pm 35 \mu \mathrm{m})$ the CCT was not correlated in diabetic retinopathy stage. They reported that even the CCT was greater in PDR group $(582 \mu \mathrm{m})$, eyes with NPDR had lower CCT $(558 \mu \mathrm{m})$ than non-diabetic eyes $(565 \mu \mathrm{m})$ the measured by US pachymetry.

Galgauskas and coworkers [14] reported that even no differences were observed in endothelial parameters between subjects with DM and control groups and no correlations among $\mathrm{HbA} 1 \mathrm{c}$, duration of $\mathrm{DM}$, but only the CCT $(566.7 \pm 35.7$ $\mu \mathrm{m})$ was higher in diabetic patients than in the control group $(550.0 \pm 56.4 \mu \mathrm{m})$ similar to other reports.

In presenting study the CCTs which were measured by non-contact pachymetry, in both subject with DM $(528 \mu \mathrm{m})$ and control group $(530 \mu \mathrm{m})$ were lower than the other reports measured by US pachymetry. Our results were similar to Wong et al. report in which the same CCTs measured by either Scheimpflug imaging $(536.7 \mu \mathrm{m})$ (Pentacam HR) or OCT (Cirrus HD-OCT) $(535.1 \mu \mathrm{m})$, were less than measure by US pachymetry 
$(542.6 \mu \mathrm{m})$ [17]. The results of CCT can be different due to evaluating instruments. Noncontact assessments of corneal thickness, that we preferred should be more reliable option than contact US pachymetry since it does not require indentation force which may cause inter and intra-observer difference.

In contrast to finding in most of the other reports, even not statistically significant, our subjects with NPDR had lower CCT $(525 \mu \mathrm{m})$ than the normal subjects $(530.41 \mu \mathrm{m})$ in preoperative stage. Each of our subjects had under medical control therefore even the retina had some clinical signs about the DM; the CCT did not affected by this systemic metabolic syndrome yet.

Wong et al [17] compared the corneal parameters in preoperative and postoperative period in normal subjects and found no difference at mount 1 postoperatively. Praveen et al [18] found the similar results. Fukuda et al [19] found a statisticallysignificant differenceinCTafterphacoemulsification in early postoperative period; however, the difference was no longer significant at 2 weeks. Tsaousis et al [20] qualitatively compared corneal edema between diabetics and nondiabetics subjects after phacoemulsification surgery, at the last visit at second week. They observed that incidence of corneal edema was higher than normal subject. According to their opinion 2 weeks postoperative follow up is sufficient in evaluation of corneal edema. In presenting study we preferred to objectively evaluate the whole subjects in longer period comparing to other studies.

Shakya et al [21] evaluated surgical induced corneal edema in 33 eyes with DM and compared with 63 normal eyes. They observed that even there was no clinically difference in any preoperative corneal examination between the diabetic and non-diabetic groups, the clinically observable corneal edema after surgery was significantly higher in the diabetic group than in the non-diabetic group.

We found that a significant increment in preoperative CCT $(525 \mu \mathrm{m})$ comparing to postoperative CCT $(538 \mu \mathrm{m})$ in subject with DM, but in aged match normal subjects the preoperative $(530 \mu \mathrm{m})$ and postoperative $(531 \mu \mathrm{m})$ CCT was very similar at first month. In the presenting study even the preoperative CCT was lower in subjects with DM the postoperative CCT was higher than that of normal subjects. This result corroborates analogous results from previous studies that corneal recovery response different in patients with DM than normal subjects.

As far as we know our research is the first study evaluating behavior of corneal endothelium, without any preexisting risk factor, under the same operative condition even subjects had metabolic control. And as far as we concern our study is the only one study that CCT of treatment native diabetic eyes had lower than the normal subjects CCT. Further studies are need for evaluation of different diabetic stage to gain more information about the corneal response to surgical traumas.

\section{References}

1. Storr-Paulsen A, Singh A, Jeppesen H, Norregaard JC, Thulesen J. Corneal endothelial morphology and central thickness in patients with type II diabetes mellitus. Acta Ophthalmol. 2014; 92(2): 158-160. doi: 10.1111/ aos. 12064
2. Baradaran-Rafii A, Rahmati-Kamel M, Eslani M, Kiavash V, Karimian F. Effect of hydrodynamic parameters on corneal endothelial cell loss after phacoemulsification. J Cataract Refract Surg. 2009; 35(4):732-737. doi: 10.1016/j.jcrs.2008.12.017

3. Airiani S, Trokel SL, Lee SM, Braunstein RE. Evaluating central corneal thickness measurements with noncontact optical low -coherence reflectometry and contact ultrasound pachymetry. Am J Ophthalmol. 2006; 142(1):164-165. doi:10.1016/j.ajo.2006.01.043

4. Dedov I, Maslova O, Suntsov Y, Bolotskaia L, Milenkaia T, Besmertnaia L and et al. Prevalence of diabetic retinopathy and cataract in adult patients with type 1 and type 2 diabetes in Russia. Rev Diabet Stud. 2009; 6(2): 124-129. doi: 10.1900/RDS.2009.6.124

5. Tavakoli M, Kallinikos $\mathrm{P}$, Iqbal A and et al. Corneal confocal microscopy detects improvement in corneal nerve morphology with an improvement in risk factors for diabetic neuropathy. Diabet Med. 2011; 28(10): 1261-7. doi: 10.1111/j.1464-5491.2011.03372.x.

6. Lundberg B, Jonsson $M$, Behndig A. Postoperative corneal swelling correlates strongly to corneal endothelial cell loss after phacoemulsification cataract surgery. Am J Ophthalmol. 2005; 139(6):1035-1041. doi:10.1016/j.ajo.2004.12.080

7. Park JH, Lee SM, Kwon JW and et al. Ultrasound energy in phacoemulsification: A comparative analysis of phacoemulsificationchop and stop-and-chop techniques according to the degree of nuclear density. Ophthalmic Surg Lasers Imaging. 2010; 41(2):236-241. doi: 10.3928/15428877-20100303-13

8. Davison JA. Results of endocapsular phacofracture debulking of hard caratacts. Clin Ophthalmol 2015; 9: 1233-1038. doi: 10.2147/OPTH.S85939

9. Storr-Paulsen A, Norregaard JC, Ahmed S, Storr-Paulsen T, Pedersen TH. Endothelial cell damage after cataract surgery: Divide-and-conquer versus phaco-chop technique. J Cataract Refract Surg. 2008; 34(6): 9961000. doi: 10.1016/j.jcrs.2008.02.013.

10. Davison JA, Cionni RJ, Snowdon JR, Swartz K, Wears S, Simmons S, Barker $A$ and et al. Simultaneous surgeon and side-view video analysis comparing in situ fracture and stop- and-chop phacoemulsification. $J$ Cataract Refract Surg. 2005; 31(2):274-279. doi: 10.1016/j.jcrs.2004.09.026

11. Rekas M, Montes-Mico R, Krix-Jachym K, Klus A, Stankiewicz A, FerrreBlasco T. Comparison of torsional and longitudinal modes using phacoemulsification parameters. J Cataract Refract Surg.2009; 35(10): 1719-1724. doi: 10.1016/j.jcrs.2009.04.047

12. Vasavada AR, Praveen MR, Vasavada VA and et al. Impact of high and low aspiration parameters on postoperative outcomes of phacoemulsification: randomized clinical trial. J Cataract Refract Surg. 2010; 36(4): 588-93. doi: 10.1016/j.jcrs.2009.11.009

13. Calvo-Maroto AM, Cerviño A, Perez-Cambrodí RJ, García-Lázaro S, Sanchis-Gimeno JA. Quantitative corneal anatomy: Evaluation of the effect of diabetes duration on the endothelial cell density and corneal thickness. Ophthalmic Physiol Opt. 2015; 35(3): 293-8. doi: 10.1111/opo.12191

14. Galgauskas S, Laurinavičiūtè $G$, Norvydaitè D, Stech S, Ašoklis R. Changes in choroidal thickness and corneal parameters in diabetic eyes. Eur $J$ Ophthalmol.2016; 26(2): 163-7. doi: 10.5301/ejo.5000677

15. Senćanić $\mathrm{I}$, Stamenković $\mathrm{M}$, Jovanović $\mathrm{V}$, Babović $\mathrm{S}$, Jakšić $\mathrm{V}$, Marković $\mathrm{P}$. Influence of diabetes mellitus on corneal thickness. Srp Arh Celok Lek. 2014; 142: 529-34.

16. Ozdamar Y, Cankaya B, Ozalp S, Acaroglu G, Karakaya J, Ozkan SS. Is there a correlation between diabetes mellitus and central corneal thickness? J Glaucoma. 2010; 19(9): 613-6. doi: 10.1097/IJG.0b013e3181ca7c62

17. Wong MM, Shukla AN, Munir WM. Correlation of corneal thickness and volume with intraoperative phacoemulsification parameters using Scheimpflug imaging and optical coherence tomography. J Cataract Refract Surg. 2014; 40(12): 2067-75. doi: 10.1016/j.jcrs.2014.03.031

18. Praveen MR, Koul A, Vasavada AR. DisCoVisc versus the soft-shell technique using Viscoat and Provisc in phacoemulsification: Randomized clinical trial. J Cataract Refract Surg. 2008; 34(7): 1145-51. doi: 10.1016/j. jcrs.2008.03.019 
19. Fukuda S, Kawana K, Yasuno Y, Oshika T. Wound architecture of clear corneal incision with or without stromal hydration observed with 3-dimensional optical coherence tomography. Am J Ophthalmol. 2011; 151(3):413-9. doi: 10.1016/j.ajo.2010.09.010

20. Tsaousis KS, Panagiotou DZ, Kostopoulou E, Vlatsios V, Stampouli D. Corneal oedema after phacoemulsification in the early postoperative period: A qualitative comparative case-control study between diabetics and non-diabetics. Ann Med Surg (Lond). 2015; 5; 67-71.
21. Shakya K, Pokharel S, Karki KJ, Pradhananga C, Pokharel RP, Malla OK. Corneal edema after phacoemulsification surgery in patients with type II diabetes mellitus. Nepal J Ophthalmol. 2013; 5(2): 230-4. doi: 10.3126/ nepjoph.v5i2.8734 